09

\title{
Теплопередача в капле воды с красителем и наночастицами при двойном лазерном воздействии
}

\author{
(C Н.А. Мыслицкая, ${ }^{1}$ Р.Ю. Боркунов, ${ }^{2}$ М.В. Царьков, ${ }^{2}$ В.А. Слежкин, ${ }^{1}$ И.Г. Самусев, ${ }^{2}$ Ю.Н. Антипов, ${ }^{1}$ \\ B.В. Брюханов ${ }^{2}$ \\ ${ }^{1}$ Калининградский государственный технический университет, \\ 236022 Калининград, Россия \\ ${ }^{2}$ Балтийский федеральный университет им. И. Канта, \\ 236041 Калининград, Россия \\ e-mail: myslitskaya@gmail.com
}

Поступило в Редакцию 8 июля 2019 г.

В окончательной редакции 31 января 2020 г.

Принято к публикации 12 февраля 2020 г.

\begin{abstract}
Исследована теплопередача в водяной капле с эозином и абляционными наночастицами серебра при лазерном видимом стационарном $(\lambda=532 \mathrm{~nm})$ и инфракрасном импульсном $(\lambda=10.6 \mu \mathrm{m})$ воздействии (VisIR-двойное лазерное воздействие) в интервале температур от 0.2 до $50^{\circ} \mathrm{C}$. Установлено, что после Vis-IRвоздействия происходит нагрев колебательной системы триплетных состояний молекул красителя в капле с генерацией термолюминесценции, кинетика затухания которой отражает новое распределение электронноколебательных мод в спектре флуоресценции молекул красителя. При малых размерах капли с наночастицами серебра $(d<1.0 \mathrm{~mm})$ после инфракрасного воздействия $(\tau=50 \mathrm{~ms})$ наблюдается генерация теплового фронта с излучением термолюминесценции, перемещающегося в водяной среде со скоростью $0.85 \mathrm{~cm} / \mathrm{s}$. Проведено моделирование процессов теплопередачи в капле при образовании тепловой волны.
\end{abstract}

Ключевые слова: двойное лазерное возбуждение, теплопередача, температуропроводность, флуоресценция, термолюминесценция, водяная капля, эозин, абляционные наночастицы серебра.

DOI: $10.21883 / J T F .2020 .08 .49543 .264-19$

\section{Введение}

Исследование тепловых процессов в водяной капле, содержащей металлические наночастицы (НЧ), молекулы органических веществ и биологических объектов, представляет практический интерес для изучения теплопередачи и кинетических процессов массопереноса под влиянием электромагнитного излучения [1-6]. Значительное количество исследований связано с тепловым, радиационным и лазерным воздействиями на висячую каплю или каплю, осажденную на гидрофобную или гидрофильную поверхность [7-11], а также со спектральными и оптическими методами получения тепловых и кинетических параметров капли при вибрационных и акустических воздействиях [12-14]. При этом нетрудно найти в литературе различные инженерные схемы экспериментальных установок, например, в работе [15] приводятся различные типы генерации и регистрации тепловых потоков в капле с различными ингредиентами в составе при наличии градиента температуры и термодиффузии (эффект Соре) [16-18]. Таким образом, капли микронных размеров чистых жидкостей или растворов на их основе, а также дисперсных систем, в том числе с НЧ, являются важнейшим объектом исследования физических процессов в конденсированных средах.

Выбор научного направления исследований водяной капли был основан на достижениях в области нанофотоники конденсированнных сред, например, в рабо- тах [19-20], где и разработаны новые методы получения сведений о тепло-фотофизических процессах в жидкости [21]. В настоящей работе исследованы процессы преобразования энергии электронно-колебательного возбуждения в висячей капле воды с красителем и НЧ серебра в диапазоне температур от 0.2 до $50^{\circ} \mathrm{C}$. Разработана экспериментальная установка и методика лазерного видимого $(\lambda=532 \mathrm{~nm})$ и инфракрасного (ИК) воздействия $(\lambda=10.6 \mu \mathrm{m}, \mathrm{Vis}-\mathrm{IR})$ на различные физические среды. Целью экспериментального исследования было изучение спектрально-кинетических и тепловых процессов в различных областях микрокапли и проведение их математического моделирования.

\section{1. Методика}

Объектом исследования являлись капли водных растворов эозина с НЧ серебра, висящие на шарике хромель-копелевой термопары диаметром $0.2 \mathrm{~mm}$. Во всех растворах концентрация эозина составляла $5 \cdot 10^{-5} \mathrm{M}$, а концентрация НЧ серебра (средний радиус НЧ составлял $38 \mathrm{~nm}$ ) была различной. НЧ получали методом лазерной абляции пластины серебра в воде на фемтосекундном лазерном комплексе Avesta TETA-25 в режиме $\tau=60 \mathrm{fs}$, энергия $130 \mu \mathrm{J}$. Диаметры $d$ капель составляли 1.92, 1.0 и $0.5 \mathrm{~mm}$. Раствор выдавливали через иглы с различными внутренними диа- 
метрами, что позволяло получать капли разных размеров. Дополнительно размер капель оценивали с помощью микроскопа и видеокамеры. Спектральные и кинетические характеристики люминесценции (флуоресценции, замедленной флуоресценции (DFI), фосфоресценции молекул эозина исследовали на приборе Fluorolog-3 фирмы Horiba (Франция-Япония). Двойное лазерное Vis-IR-воздействие было реализовано следующим образом: сначала возбуждалась стационарная флуоресценция образца при помощи полупроводникового лазера ASG-1032 $(\lambda=532 \mathrm{~nm}, W=1-50 \mathrm{~mW})$, затем происходило возбуждение капли одиночным импульсом $\mathrm{CO}_{2}$-лазера $(\lambda=10.6 \mu \mathrm{m}$, длительность импульса $\tau=50-250 \mathrm{~ms}$, фронт $\Delta \tau=1.0 \mathrm{~ms})$. Капля полностью освещалась Vis-IR-излучением лазеров. Следует отметить, что через время $\Delta \tau \approx 15 \mathrm{~s}$ происходили фотохимические процессы деградации капли с красителем и ее последующее полное высыхание. Температуру капли измеряли хромель-копелевой термопарой с точностью $\pm 0.2^{\circ} \mathrm{C}$.

\section{2. Экспериментальные результаты}

Генерацию тепловых процессов в водяной капле с НЧ (нанометровыми источниками тепла в результате воз-

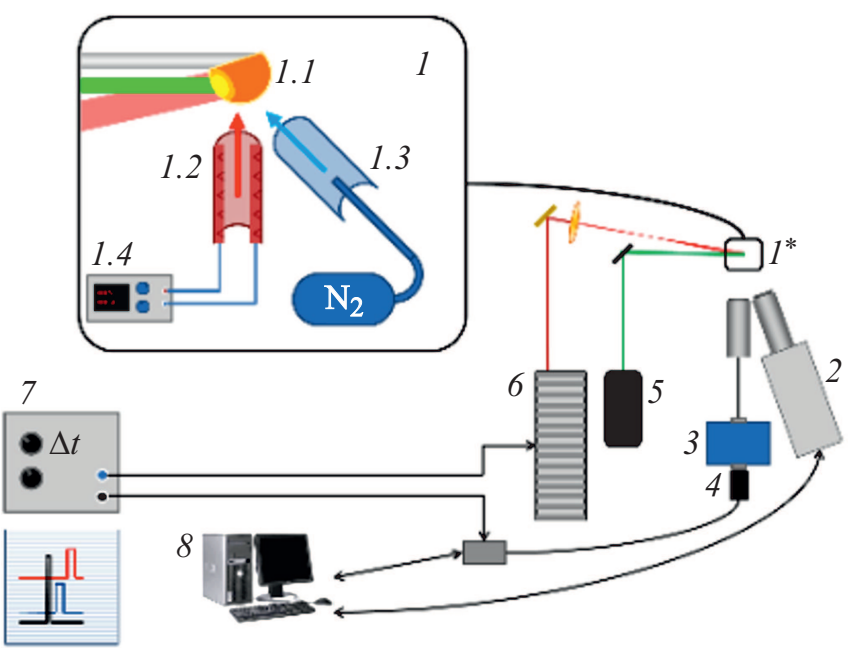

Рис. 1. Схема расположения элементов низкотемпературного стенда для изучения термолюминесценции молекул эозина в водяной капле с наночастицами абляционного серебра: 1 - блок с держателем капли: 1.1 - капля на микрошприце и направление входа ИК-воздействия и зеленого луча, 1.2 - тепловая пушка для нагрева капли, 1.3 - генератор азота из Дьюара, 1.4 - блок управления; 2 - высокоскоростная видеокамера MotionPro X4 (REDLAKE) телескопом; 5 - полупроводниковый лазер ASG-1032 $(\lambda=532 \mathrm{~nm}$, $W=1-50 \mathrm{~mW}) ; 6$ - ИК-лазер C-20A $(\lambda=10.6 \mu \mathrm{m}$ длительностью $\tau_{\mathrm{IR}}=50-250 \mathrm{~ms}$ и фронтом $\left.\Delta \tau \approx 1.0 \mathrm{~ms}\right) ; 7-$ двухканальный генератор импульсов Г5-56 и эпюры импульсов с осциллографа; 8- компьютер со специализированной программой обработки сигналов. Полная схема установки представлена в [21].

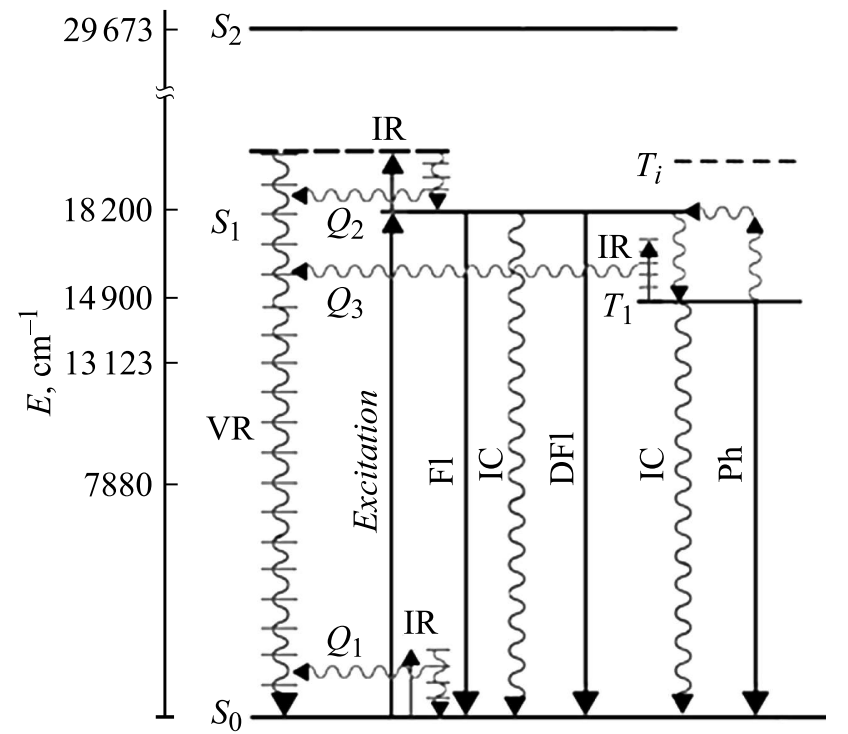

Рис. 2. Диаграмма электронно-колебательных переходов в молекуле эозина $\left(C=5 \cdot 10^{-5} \mathrm{M}\right)$ при двойном лазерном (Vis-IR) фотовозбуждении капли с красителем: возбуждение лазером $\lambda=532 \mathrm{~nm}$; флуоресценция (Fl); внутренняя конверсия (IC); ИК-возбуждение (IR) $(\lambda=10.6 \mu \mathrm{m})$; колебательная релаксация (VR); замедленная флуоресценция (DFl); фосфоресценция (Ph). Электронные состояния молекулы красителя: $S_{0}, S_{1}$, $S_{2}, T_{1}, T_{i}$. Теплоты $Q_{1}, Q_{2}, Q_{3}$ - выделяемые в системе в результате колебательной релаксации.

буждения) в образце создавали методом Vis-IR-возбуждения (рис. 1) [21]. Капли водных растворов исследовали при комнатной и низкой температурах вплоть до температуры их замерзания $\left(\sim 0.1^{\circ} \mathrm{C}\right)$. Vis-IR-возбуждение концентрировалось на капле с термопарой, одновременно с этим исследовались кинетика и энергетика свечения люминесценции [21]. Сначала осуществляли воздействие на каплю раствора с эозином стационарным лазерным возбуждением $(\lambda=532 \mathrm{~nm})$, затем - импульсным воздействием $\mathrm{c}$ помощью $\mathrm{CO}_{2}$-лазера $(\lambda=10.6 \mu \mathrm{m})$. Следует отметить, что температура капли практически не изменялась при воздействии только лазерного излучения с длиной волны $\lambda=532 \mathrm{~nm}$ и находилась в пределах от 18 до $20^{\circ} \mathrm{C}$. После ИК-воздействия температура капли повышалась до $50^{\circ} \mathrm{C}$. Рассмотрим процессы преобразования электромагнитной энергии в капле после Vis-IR-воздействия в отсутствие НЧ серебра.

Последовательное и совместное Vis-IR-воздействие создает спектр электронно-колебательных процессов преобразования электромагнитной энергии молекул эозина в водяной капле, представленный на диаграмме (рис. 2) без учета фотохимических преобразований в красителе.

Первоначально была исследована флуоресценция при Vis-IR-возбуждении раствора. После ИК воздействия $(\tau=100 \mathrm{~ms})$ на $S_{1^{-}}$и $T_{1}$-состояния эозина в капле было зарегистрировано смещение (около $10 \mathrm{~nm}$ ) макси- 
мума спектра флуоресценции через время $\Delta \tau \approx 50 \mathrm{~ms}$ в красную область спектра при небольшом увеличении интенсивности и образовании „плеча“ в спектре в интервале длин волн $560-580 \mathrm{~nm}$. Анализируя ИК-спектр эозина [22], можно заметить, что валентные и деформационные колебания групп молекулы красителя $(-\mathrm{C}-\mathrm{C}-$, $\mathrm{C}-\mathrm{O}-$ и $-\mathrm{C}-\mathrm{H}-)$ сосредоточены в основном в области $\Delta v=600-1600 \mathrm{~cm}^{-1}(\lambda \approx 540 \mathrm{~nm}$, флуоресценция), а в области спектра флуоресценции $(560-580 \mathrm{~nm})$ усиливаются колебания -H-O-Н-групп, что, в свою очередь, приводит к нагреву капли, возможно, даже более значительному в связи с высокой теплопроводностью воды [23]. Таким образом, ИК-воздействие на каплю индуцирует новое распределение электронно-колебательных мод в спектре флуоресценции молекул эозина, проявляющееся в кинетических процессах дезактивации возбужденных состояний молекул красителя в капле.

Рассмотрим кинетические процессы дезактивации электронно-колебательной энергии при стационарном лазерном возбуждении $(\lambda=532 \mathrm{~nm})$ синглетных и триплетных состояний молекул эозина (рис. 2). В отсутствие ИК-возбуждения в капле наблюдаются различные виды молекулярной люминесценции: флуоресценция $\left(\tau_{\mathrm{fl}} \approx 1 \mathrm{~ns}\right)$, замедленной флуоресценции $(\mathrm{DFI})$ $\left(\tau_{\mathrm{DFI}} \approx 1 \mathrm{~ms}\right)$ и фосфоресценция [24]. Известно, что в отсутствие концентрационного тушения флуоресценции молекул эозина в водных растворах имеет место равенство квантовых выходов: $\varphi_{T} \approx \varphi_{\text {fil }}$. Вероятность внутренней конверсии (IC) у молекул эозина незначительна, а квантовые выходы DFI и фосфоресценции молекул эозина в таких средах по нашим измерениям имеют величины одного порядка $\left(10^{-2}-10^{-3}\right)$.

При ИК-воздействии на возбужденные электронноколебательные состояния $S_{0}, S_{1}, T_{1}$ молекул красителя происходит нагрев капли с выделением тепловых энергий $Q_{1}, Q_{2}, Q_{3}$, величины которых зависят от плотности колебательных уровней (рис. 2). Следует отметить, что излучение ИК-импульса проходило вдоль диаметра капли и полностью поглощалось по закону Бера на длине, равной диаметру капли $(d=1.92 \mathrm{~mm}) \mathrm{c}$ коэффициентом поглощения $\gamma \approx 1000 \mathrm{~cm}^{-1}$ [25] и оптической плотностью $D=1.92 \cdot 10^{-4}$. Излучение ИК-импульса $\left(\lambda=10.6 \mu \mathrm{m}, \Delta \tau_{\mathrm{IR}}=50-100 \mathrm{~ms}\right)$ поглощалось в соответствии со спектром поглощения молекулами красителя и воды, а также сопровождалось очень быстрой слабой вспышкой света во всем объеме капли. Энергия электронно-колебательного возбуждения $Q_{2}$ рассеивается в результате IC $\left(\tau_{\mathrm{OD}} \approx 10^{11}-10^{13} \mathrm{~s}^{-1}\right)$ при переносе колебательной энергии между молекулами и средой [26], а также при переходе на электронноколебательные уровни $T_{1}$-состояния в результате интеркомбинационной конверсии (ИКК) $S_{1} \rightarrow T_{1}$ с константой скорости $1 \cdot 10^{8} \mathrm{~s}^{-1}$ [24]. При этом в результате поглощения энергии $Q_{3}$, происходит увеличение температуры системы, в которой молекулы эозина находятся в $T_{1}$-состоянии (согласно распределению Больцмана). В отсутствие стационарного возбуждения в системе флуоресценции молекул эозина в капле не возникает, и среда нагревается только в результате импульсного ИК-воздействия (за счет рассеяния колебательной энергии $Q_{1}$ на основном электронно-колебательном уровне $S_{0}$ молекул эозина).

Таким образом, лазерное импульсное ИК-воздействие на молекулы эозина в водяной капле будет приводить к увеличению концентрации триплетных состояний $T_{1} \mathrm{c}$ большим временем жизни (порядка $1 \mathrm{~ms}$ ).

\section{1. Капля диаметром $d=1.92 \mathrm{~mm}$}

Нагрев ИК-излучением электронно-колебательной системы $S_{1}$ - и $T_{1}$-состояний молекул красителя в воде приводит к ускорению обратной ИКК $T_{1} \rightarrow S_{1}$ (рис. 1) [24] и увеличению интенсивности свечения термоактивированной DFI, спектр которой совпадает со спектром быстрой флуоресценции красителя. Интенсивность DFI, дополнительно инициируемой ИК-импульсом, в работе [21] была названа термолюминесценцией (ТЛ) по аналогии со спонтанной термоактивированной молекулярной DFI [24]. Было установлено, что после окончания действия ИК-имульса с прямоугольным временным профилем $(\Delta \tau \approx 1.0 \mathrm{~ms})$ происходит практически линейное возрастание интенсивности ТЛ молекул эозина в капле с характерным временем нарастания $0.1-0.2 \mathrm{~s}$, а затем ее последующее затухание $\left(\tau_{\mathrm{TL}} \approx 10-20 \mathrm{~s}\right)$ при комнатной температуре. На рис. 3 представлены кинетические кривые ТЛ молекул эозина в капле на длинах волн $\lambda=540$ и $570 \mathrm{~nm}$.

После прекращения ИК-воздействия и дальнейшем стационарном возбуждении $(\lambda=532 \mathrm{~nm})$ капли с эозином происходило затухание ТЛ, сопровождавшееся охлаждением капли в результате совокупности колебательных релаксационных процессов в системе, соответствующим переходам из $T_{1}$ - и $S_{1}$-состояний (рис. 2) в равновесное основное колебательное состояние. Для исследования кинетики затухания ТЛ в различных микрообъемах капли была разработана программа обработки изображений для независимого анализа затухания интенсивности и времени жизни ТЛ красителя в капле [21]. На рис. 3 представлены видеокадры свечения ТЛ в точках „,головы“ $(a)$ и „хвоста“ $(b)$ водяной капли с молекулами эозина, а также кинетика затухания ТЛ при комнатной температуре после ИК-воздействия. Сравнивая кинетические особенности кривых затухания ТЛ в различных точках водяной капли с красителем (рис. 3), можно отметить различие в форме кинетики ТЛ в вышеобозначенных точках. Формы кинетических кривых затухания ТЛ различаются по своему виду в различных областях спектра люминесценции и значительно отличаются друг от друга (рис. 3,c). Кроме того, в „голове“ капли (рис. $3, a$ ) наблюдается рост интенсивности ТЛ под влиянием ИК-воздействия и последующее ее затухание. При этом система возвращается в низшее колебательное состояние $T_{1}$ - и $S_{1}$-уровней при комнатной температуре в соответствии законом распределения Больцмана. 

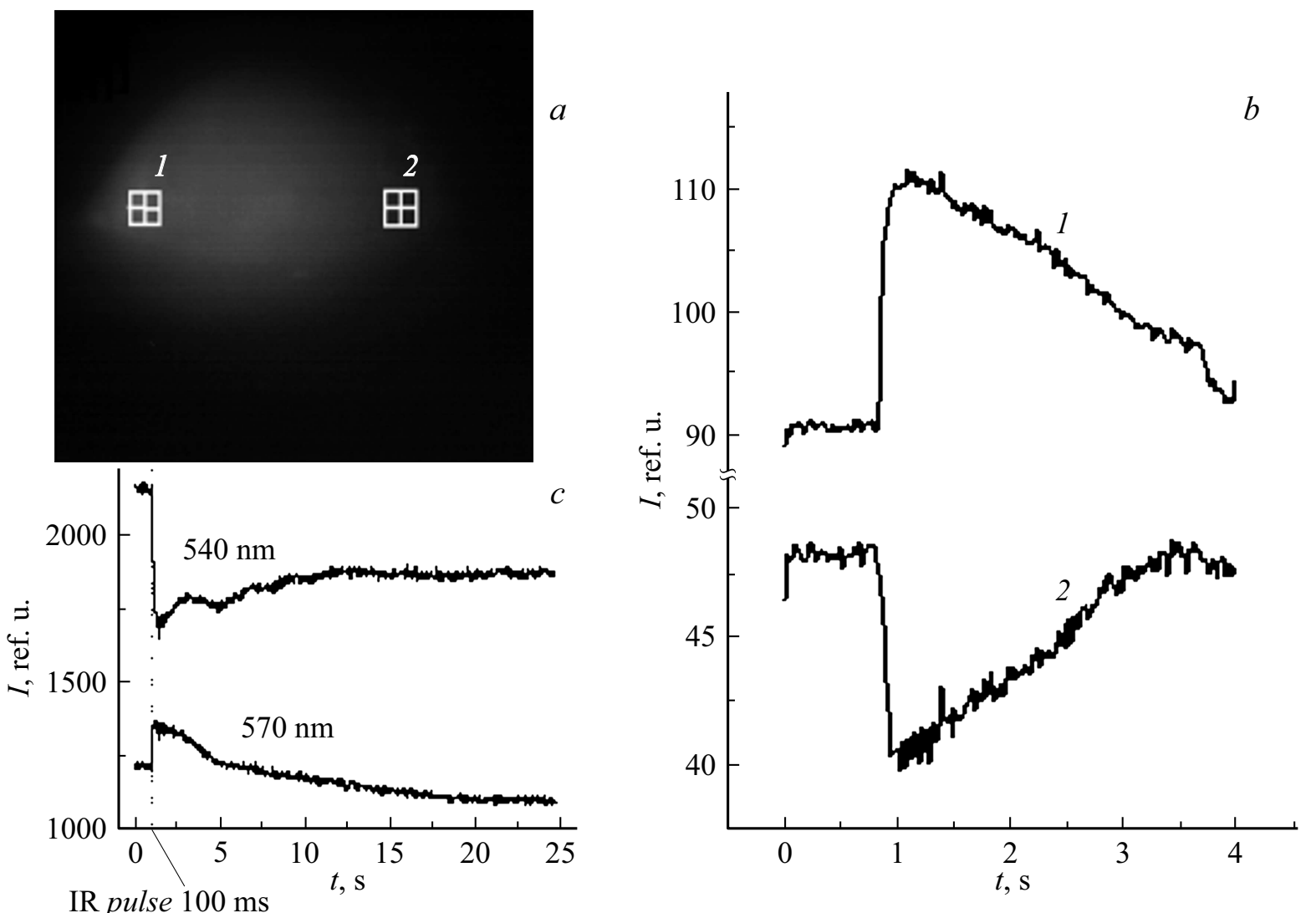

Рис. 3. Видеокадры $(a)$ и кинетические кривые затухания $(b)$ свечения ТЛ водяной капли с молекулами эозина $\left(C=5 \cdot 10^{-5} \mathrm{M}\right)$ в выбранных точках площадью $8.29 \cdot 10^{-2} \mathrm{~mm}^{2}$ на поверхности в начале („голова“) (1) и конце („хвост“) (2) при комнатной температуре после Vis-IR-воздействия. $c$ - представлены кинетические кривые затухания ТЛ на длинах волн $\lambda=570 \mathrm{~nm}$ („голова“ $)$ и $\lambda=540 \mathrm{~nm}($ „хвост“") после Vis-IR-воздействия на молекулы эозина в водяной капле.

Наоборот, после ИК-воздействия в „хвосте“ капли наблюдается тушение ТЛ, а затем экспоненциальный рост интенсивности ТЛ в результате нагревания капли до комнатной температуры (рис. $3, b$ ).

Представляло интерес исследование процессов затухания ТЛ молекул эозина в любой точке капли вдоль направления распространения ИК-возбуждения (см. направление ИК-луча в капле, рис. 1). Были измерены кинетические кривые ТЛ светящихся микробъемов жидкости (пиксели) вдоль диаметра капли с шагом $0.1 \mathrm{~mm}$. Результаты исследований представлены на рис. 4.

Анализ кривых затухания ТЛ в выбранных координатах капли и их сравнение с кинетикой термо-ЭДС термопары в капле (рис. 4) при охлаждении показали, что имеется функциональная идентичность времен дезактивации процессов. Было экспериментально установлено, что ТЛ описывается экспоненциальной функцией (погрешность составляет 7-10\%):

$$
I_{\mathrm{TL}}=\beta \cdot I_{\mathrm{TL}}^{0} \exp \left(-\left(t-t_{0}\right) / \tau_{\mathrm{TL}}\right),
$$

где $I_{\mathrm{TL}}, I_{\mathrm{TL}}^{0}$ интенсивности ТЛ в „голове“ капли; $\beta-$ коэффициент, зависящий от выбранного в эксперименте диапазона температур, формы капли (поверхности), наличия в нее включений и т.п.; $t_{0}-$ выбранный на экспоненциальном участке кривой затухания ТЛ начальный момент времени; $\tau_{\mathrm{TL}}-$ время жизни ТЛ. В настоящей работе было предположено, что в условиях проведения эксперимента коэффициент $\beta$ является практически постоянной величиной. Таким образом, величины $I_{\mathrm{TL}}$ и $\tau_{\mathrm{TL}}$ пропорциональны локальной термодинамической температуре среды и, следовательно, последнюю можно косвенно определить по их значениям.

Указанные изменения формы кинетических кривых затухания ТЛ эозина в капле наблюдались при комнатной температуре в каждом пикселе поверхности капли по всей длине диаметра от „головы“ до „хвоста““ (рис. 4, $a$ ). Эти изменения указывают на трансформацию свечения в другой тип примерно в центре капли (на расстоянии от поверхности (вдоль диаметра), равном $1.2 \mathrm{~mm}$ ). Было установлено, что одновременно с трансформацией кинетики ТЛ после ИК-воздействия (рис. $4, a$ ) в этой точке наблюдаются спектральные и энергетические изменения флуоресценции молекул эозина в капле в диапазоне длин волн 540-580 nm (рис. 3,c).

С целью изучения физических причин спектральнокинетических трансформаций ТЛ эозина в капле в ра- 

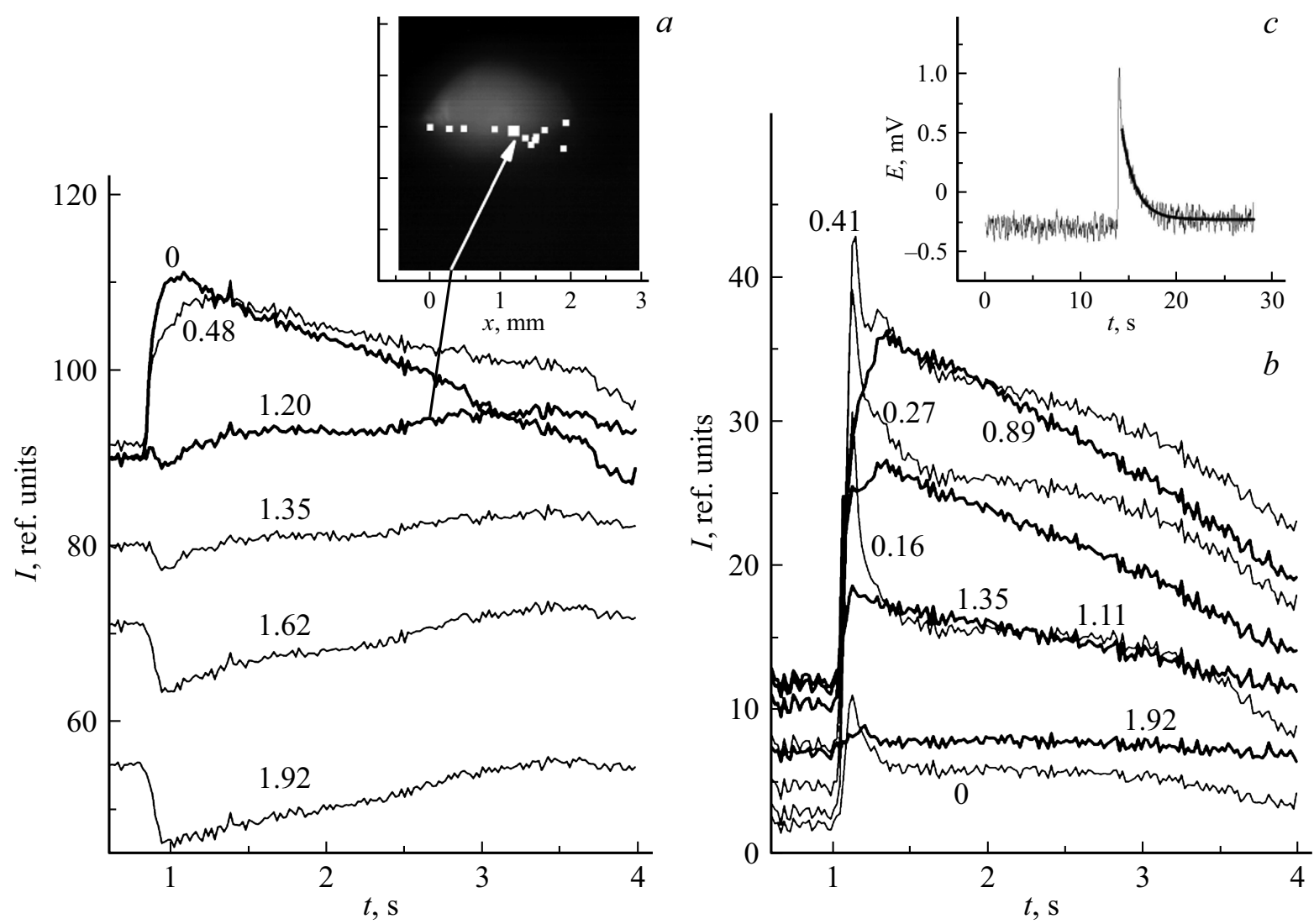

Рис. 4. Кинетические кривые затухания ТЛ молекул эозина $\left(C=5 \cdot 10^{-5} \mathrm{M}\right)$ в некоторых точках после ИК-воздействия при комнатной температуре $(a)$ и вблизи нуля $(b)\left(\approx 0.2^{\circ} \mathrm{C}\right)$. На рисунках обозначены значения координат кривых затухания ТЛ, соответсвующих размеру капли $(1.92 \mathrm{~mm})$, от „головы“ до „хвоста“ вдоль капли по лучу распространения возбуждения. $c-$ представлена кинетическая кривая уменьшения термо-ЭДС затухания ТЛ после ИК-воздействия.

боте были реализованы низкотемпературные исследования (до температуры $0.2^{\circ} \mathrm{C}$ ) при Vis-IR-воздействии на систему. Следует заметить, что температурные эксперименты представляли определенные трудности, поскольку вблизи $0^{\circ} \mathrm{C}$ происходит почти мгновенное замерзание раствора. При этом капля оставалась жидкой и висячей на шарике термопары, в которой измерялась кинетика термо-ЭДС с помощью осциллографа.

На рис. 4 представлены кинетические кривые затухания ТЛ молекул эозина после ИК-воздействия. Сравнивая кинетику TЛ после Vis-IR-воздействия на каплю при комнатной температуре (рис. $4, a)$ и в охлажденной капле (рис. 4,b), можно заметить, что кинетика ТЛ в охлажденной капле стала только затухающей. На основании температурных исследований спектральнокинетических особенностей ТЛ эозина в капле можно предположить, что при понижении температуры капли раствора до его кристаллизации происходит уменьшение количества колебательных мод $-\mathrm{H}-\mathrm{O}-\mathrm{H}-$ групп в результате торможения колебательных процессов при понижении температуры [27].

Таким образом, впервые методом комбинированного Vis-IR-воздействия на электронно-колебательную систему молекул эозина в водяной капле при низкой тем- пературе было обнаружено, что колебательные моды -H-O-H- в спектре флуоресценции практически исчезают. При этом вдоль диаметра капли наблюдается исключительно затухающий характер кинетики ТЛ молекул эозина (рис. 4, $b$ ), который обусловлен только низкочастотными колебательными модами $(-\mathrm{C}-\mathrm{C}-$, $-\mathrm{C}-\mathrm{O}-$ и $-\mathrm{C}-\mathrm{H}-$ ) в спектре ТЛ (DFI), заполняющими энергетическую щель $T_{1}-S_{1}$ электронных состояний молекул эозина.

Во второй серии экспериментов была исследована кинетика тепловых процессов в результате Vis-IR-возбуждения и допирования раствора капли НЧ абляционного серебра. Модель лазерной генерации тепловых процессов в конденсированной среде с распределенными источниками тепла была разработана ранее в наших исследованиях $[21,28,29]$. В настоящей работе представлены новые данные по указанным тепловым процессам после ИК-воздействия на каплю с молекулами красителя и НЧ серебра при комнатной температуре и температуре капли вблизи $0^{\circ} \mathrm{C}$.

Используя метод Vis-IR-возбуждения в капле, можно оценить скорость передачи тепловой энергии вдоль диаметра после индуцированного ИК-импульсом мгновенного нагрева всех микрообластей капли по закону по- 

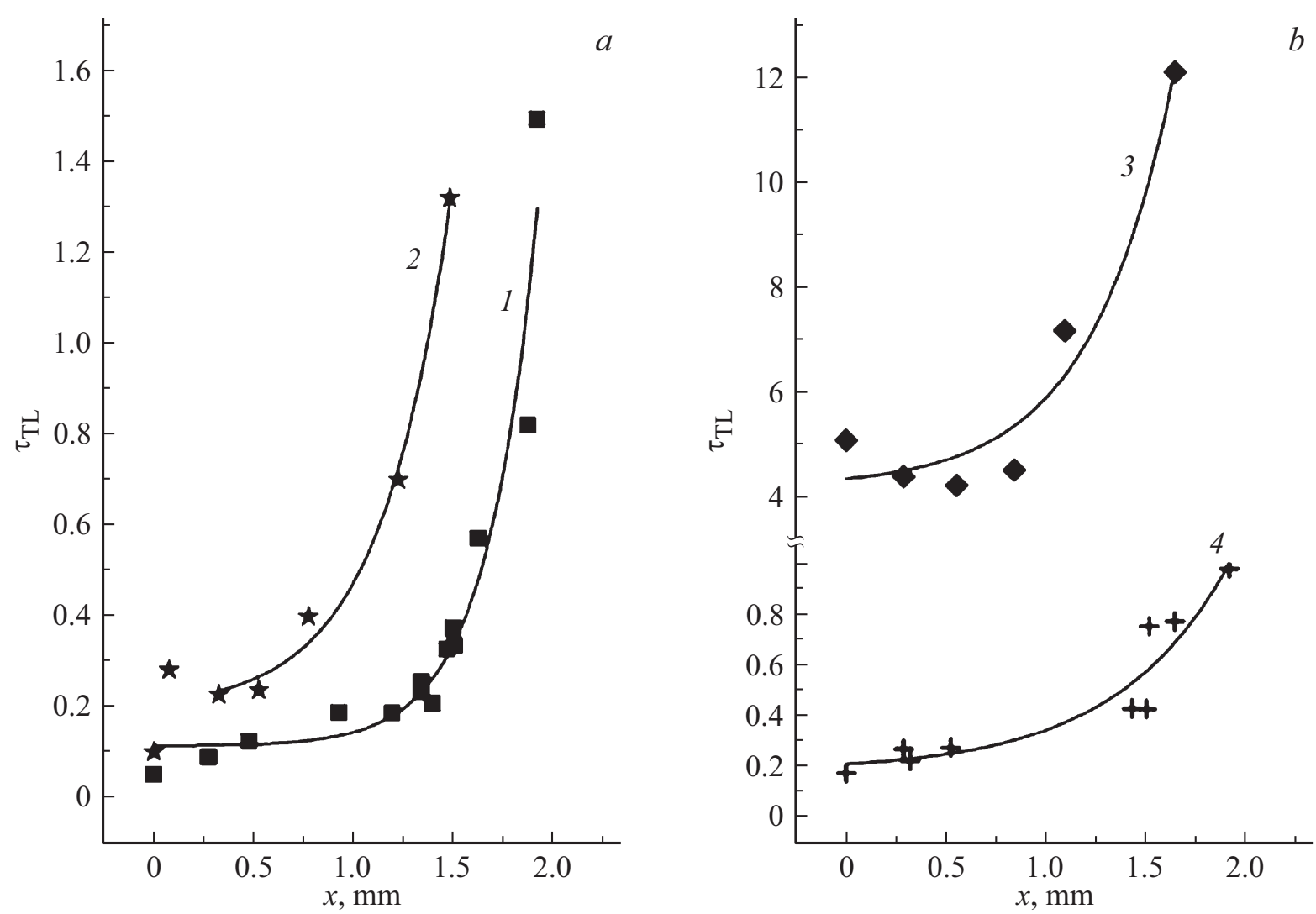

Рис. 5. Графические зависимости времен затухания $\tau_{\mathrm{TL}}(x)$ термолюминесценции молекул эозина $\left(C=5 \cdot 10^{-5} \mathrm{M}\right) \mathrm{c} H Ч$ абляционного серебра $\operatorname{Ag}_{\mathrm{NP}}\left(C_{\mathrm{Ag}}=6.9 \cdot 10^{-9} \mathrm{M}\right)$ капли воды от температуры вдоль диаметра капли: $a-$ зависимости $\tau_{\mathrm{TL}}(x)$ без НЧ при комнатной $(1)$ и низкой температурах $(2)\left(0.2^{\circ} \mathrm{C}\right) ; b-$ зависимости $\tau_{\mathrm{TL}}(x)$ с НЧ серебра при комнатной $(3)$ и низкой температурах $(4)\left(0.2^{\circ} \mathrm{C}\right)$.

глощения Бера. Передача и перераспределение тепловой энергии внутри водяной капли происходит в результате молекулярной термодиффузии и теплопередачи между молекулами эозина и НЧ серебра. В настоящей работе была сделана попытка установить количественные параметры физического процесса переноса тепловой энергии. Необходимо сделать некоторые замечания при установлении симбатности процессов ТЛ и температурной динамики во времени.

Bo-первых, измеряемые значения параметров ТЛ $\left(I_{\mathrm{TL}}\right.$ и $\left.\tau_{\mathrm{TL}}\right)$ молекул в капле пропорциональны колебательной энергии (абсолютной температуре) и концентрации триплетных молекул, которые изменяются со скоростью охлаждения самой среды. При этом регуляторный режим охлаждения капли является физически обоснованным (предположительно, экспоненциальная функция [30]). Во-вторых, коэффициенты теплопроводности и температуропроводности в диапазоне температур охлаждения от „головы“ до „хвоста“ капли могут изменяться внутри самой водяной капли $[30,31]$, в том числе при наличии в ней металлических НЧ в качестве источников тепла $[21,32]$. На рис. 5 представлены зависимости времен затухания $\tau_{\mathrm{TL}}(x)$ ТЛ молекул эозина без и с $\mathrm{HЧ}$ абляционного серебра (концентрация в растворе $6.9 \mathrm{nM}$ ) в капле воды от координаты, отсчитанной в капле вдоль ее диаметра в диапазонах температур $50-20^{\circ} \mathrm{C}$ и $50-0.2^{\circ} \mathrm{C}$ после ИК-воздействия. Аналитическое представление зависимостей было осуществлено с помощью экспоненциальной функции вида

$$
\tau_{\mathrm{TL}}=\tau_{\mathrm{TL}}^{0} \exp \left(\left(x-x_{0}\right) / l\right)
$$

Здесь $\tau_{T L}^{0}-$ время жизни ТЛ в „голове“ капли; $x_{0}-$ координата внутри капли, соответствующая началу экспоненциального участка функции $\tau_{\mathrm{TL}}(x) ; l-$ характерное расстояние, на котором время жизни ТЛ изменяется в $e$ раз.

Графически анализируя эти зависимости (рис. 5), можно заметить, что они значительно отличаются друг от друга при наличии в растворе НЧ серебра, а при низкой температуре (около $0.2^{\circ} \mathrm{C}$ ) имеется также и значительный разброс экспериментальных данных (рис. 5, кривые 2,4). Значения $x_{0}$ физически отражают увеличение времени затухания ТЛ вдоль диаметра капли от ее „головы“ до „хвоста“. Так, в диапазоне температур $0.2-50^{\circ} \mathrm{C}$ (рис. 5, кривая 2) время затухания ТЛ увеличивается по сравнению со значением при комнатной температуре (последняя входит в интервал), что является ожидаемым результатом. При наличии НЧ 
абляционного серебра время жизни ТЛ также увеличивается, однако при понижении температуры раствора среднее время изменяется незначительно $-0.41-0.55 \mathrm{~s}$. Таким образом, с понижением температуры капли в температурном диапазоне $0.2-50^{\circ} \mathrm{C}$ происходит увеличение времени жизни ТЛ, а также увеличение эффективности плазмонных процессов в результате диффузионного перемешивания и перестолкновений с НЧ серебра [33]. Механизмом изменения $\tau_{\mathrm{TL}}(x)$ можно считать наличие термодиффузии [16-18,34] в исследуемом диапазоне температур после ИК-воздействия. При этом можно оценить скорость распространения теплового возбуждения („тепловой волны“ $[17,34]$ ) и, воспользовавшись вычисленными значениями $x_{0}-\tau_{\mathrm{TL}}^{0}$ для некоторых участков кривой с экспоненциальной функции затухания ТЛ, имеем $1.92 \mathrm{~mm} / 1.5 \mathrm{~s}=1.28 \mathrm{~mm} / \mathrm{s}$. При более широком температурном интервале $0.2-50^{\circ} \mathrm{C}$ оценка скорости движения теплового фронта имеет большую ошибку.

Необходимо отметить, что полученные значения скорости передачи теплового возбуждения в воде значительно больше скорости тепловой диффузии в капле $[27,35]$, тем не менее полученные данные могут считаться лишь оценочными и требуют уточнения.

Таким образом, в капле водного раствора после импульсного ИК-воздействия $(\lambda=10.6 \mu \mathrm{m})$ на молекулярную систему, состоящую из молекул красителя и НЧ серебра, происходит направленная передача теплоты с диффузионным термоперемешиванием частиц.

Представляет интерес рассмотрение процессов теплопередачи в капле воды малого размера $(d=1.0$ и $0.5 \mathrm{~mm}$ ) при Vis-IR-воздействии.

\section{2. Капли диаметрами $d=1.0$ и $0.5 \mathrm{~mm}$}

После ИК-воздействия на каплю $(\tau=100 \mathrm{~ms})$ меньшего диаметра с эозином была обнаружена конвективная динамика усиления свечения ТЛ в ней, представленная на рис. 6 в виде видеокадров с соответствующей временной выборкой со скважностью $\tau=0.002 \mathrm{~s}$. На видеокадрах виден процесс возникновения свечения ТЛ в начале возбуждения $(0.07-0.15 \mathrm{~s})$ и в последующие моменты времени, вплоть до прохода теплового возбуждения через всю каплю за время, равное $0.95 \mathrm{~s}$, и его затухания. Физической причиной появления яркого свечения ТЛ эозина в капле является сильный нагрев колебательной системы $T_{1}$-состояния после ИК-воздействия из-за повышения плотности тепловой энергии. В связи с малыми размерами капли на ее сферической границе раздела фаз „вода-воздух“ происходят, по-видимому, оптические процессы отражения-преломления излучения ТЛ с генерацией тепловой волны с конвективным переносом тепла. Было проведено моделирование процессов переноса теплового возбуждения в различных точках сферической капли. С этой целью на изображение капли была нанесена координатная сетка (рис. 6), на которой в некоторых точках были определены значения интенсивности ТЛ, пропорциональные температуре капли, причем $\left(I_{\mathrm{TL}}\right)_{\max } \sim T_{\max }$, где $T_{\max }=50^{\circ} \mathrm{C}$.

Рассмотрим температурное поле капли воды в форме однородного шара, поверхность которого облучается ИК-лазером. Излучение поглощается внутренними слоями шара по закону Бугера. Уравнение теплопроводности для однородного шара имеет следующий вид:

$$
\begin{aligned}
& \frac{1}{a} \frac{\partial T}{\partial t}=\frac{1}{r^{2}}\left\{\frac{\partial}{\partial r}\left[r^{2} \frac{\partial T}{\partial r}\right]+\frac{\partial}{\partial z}\left\{f(z) \frac{\partial T}{\partial z}\right\}\right. \\
& \left.\times \frac{1}{\mu_{2}-\mu_{1}}+\frac{1}{f(z)} \cdot \frac{\partial^{2} T}{\partial \varphi^{2}}\right\}+Q,
\end{aligned}
$$

с областью изменения переменных: $t>0 ; 0<r<R$; $0<\varphi<2 \pi ; 0 \leq z \leq 1 ; \mu_{1}<\mu<\mu_{2}$, где $T=T(r, \varphi, z, t)-$ температура; $R$ - радиус шара; $\varphi$ - орбитальный угол; $f(z)=1-\left(\mu_{1}+\left(\mu_{2}-\mu_{1}\right) z\right)^{2} ; \mu=\cos \theta ; \theta$ - азимутальный угол, $\theta_{1}<\theta<\theta_{2} ; z=\left(\mu-\mu_{1} /\left(\mu_{2}-\mu_{1}\right) ; a-\right.$ коэффициент температуропроводности; $Q=Q(r, \varphi, z, t)-$ функция, связанная с мощностью внутренних источников $q(r, \varphi, z, t)$, определяемая выражением:

$$
Q=\frac{q}{\lambda},
$$

где $\lambda-$ коэффициент теплопроводности. Краевые условия и условие периодичности имеют вид

$$
\begin{gathered}
T(r, \varphi, z, 0)=F(r, \varphi, z), \\
\frac{\partial T}{\partial r}=-\frac{\alpha}{\lambda}\left[T(R, \varphi, z, t)-T_{s}(R, \varphi, z, t)\right], \\
T(r, \varphi, z, t)=T(r, \varphi+2 \pi, z, t) .
\end{gathered}
$$

Здесь $\alpha-$ коэффициент теплообмена шара с окружающей средой, $T_{s}(R, \varphi, z, t)$ - температура окружающей среды у поверхности шара. Решение данной задачи проведем с помощью метода конечных интегральных преобразований с ядрами $\Phi_{n}(\varphi), K_{2 n}^{2 m}(z), R_{k m}\left(\beta_{k m} r\right)$. Для получения выражения, которое может быть использовано при решении практических задач, ограничимся случаем $n=m=k=0$. Тогда решение данной краевой задачи теплопроводности для избыточной температуры $\Theta(R, \varphi, z, t)=T(R, \varphi, z, t)-T_{s}(R, \varphi, z, t)$ при $T_{s}(r, \varphi, z, t)=F(r, \varphi, z)$ примет следующий вид:

$$
\Theta(r, \mu, t)=A B(r) C(\mu) D(t),
$$

где

$$
\begin{aligned}
A= & P \int_{0}^{R} r^{2}\left(C_{10} \sin \beta_{00} r-C_{20} \cos \beta_{00} r\right) d r, \\
P= & \operatorname{arctg} \frac{\rho}{R} \cdot \frac{4 \rho q_{0}}{\lambda \beta_{00} \gamma}\left[\exp \left(a \beta_{00}^{2} \tau_{\mathrm{P}}\right)-1\right] \\
& \times R\{\exp [-\gamma R(1-\mu)-1]\},
\end{aligned}
$$

где $q_{0}-$ максимальное значение мощности внутренних источников, $\rho-$ радиус лазерного луча, $\tau_{\mathrm{P}}-$ 

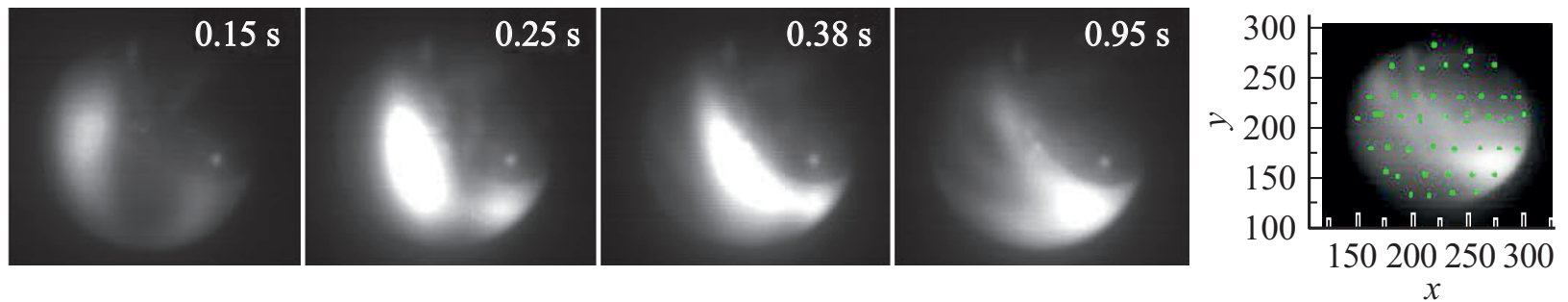

Рис. 6. Видеокадры свечения термолюминесценции молекул эозина $\left(C=5 \cdot 10^{-5} \mathrm{M}\right)$ в малой капле $(d=1.0 \mathrm{~mm})$ после VisIR-воздействия в выбранные моменты времени до полного затухания свечения. Отдельно изображена фотография капли с координатной сеткой.

длительность лазерного импульса, $\gamma$ - коэффициент поглощения в законе Бугера, равный

$$
\gamma=\frac{\ln q_{0}}{2 R}
$$

Рассмотрим приложение полученного нами решения краевой задачи теплопроводности к проведенному эксперименту с каплей воды. Из полученных нами графиков зависимости интенсивности излучения для отдельных точек капли от температуры получим следующую формулу:

$$
\Theta=0.2 I+10
$$

где $I$ - интенсивность излучения от рассматриваемой точки, $\Theta-$ соответствующая температура. При рассмотрении температуры одной и той же точки $(r$ и $\mu-$ постоянные) для моментов времени $t=t_{1}$ и $t=t_{2}$ можно определить скорость охлаждения:

$$
m=\frac{\ln \left(\Theta_{1} / \Theta_{2}\right)}{t_{2}-t_{1}} .
$$

Для точек второй верхней линии с координатами $(182,262)$ и точки нижней линии с координатами $(202,232)$ находим значения скорости $m$ охлаждения, которые оказались равными соответственно 0.428 и $0.439 \mathrm{~s}^{-1}$.

Сравнивая полученные значения $m$, видим, что темп охлаждения для двух различных точек, зависящий от коэффициента температуропроводности, практически одинаков.

Таким образом, с помощью моделирования процессов теплопроводности в капле с эозином без НЧ серебра после ИК-воздействия на каплю с диаметром $1.0 \mathrm{~mm}$ можно оценить величину термодинамической температуры лишь в некоторых светящихся точках капли. Следует заметить, что моделирование процесса теплопроводности в капле после ИК-воздействия было проведено при допущении наличия регулярного теплового режима, хотя в реальном случае (рис. 6) наблюдается конвективный режим теплопередачи внутри капли.
С помощью скоростной видеокамеры была измерена кинетика движения теплового фронта ТЛ малой капли $(d=1.0 \mathrm{~mm})$ с молекулами эозина после ИК-воздействия, скорость которого равна $\sim 0.85 \mathrm{~cm} / \mathrm{s}$, что почти совпадает с вычисленными значениями на графике рис. 5.

Исследование тепловых процессов при Vis-IR-воздействии на каплю диаметром $d=0.5 \mathrm{~mm}$ с молекулами эозина показало, что при таких размерах капли наблюдается свечение ТЛ высокой интенсивности, охватывающее всю каплю, а затухание происходит по экспоненциальному закону. При этом капля быстро испаряется, о чем будет сообщено в дальнейших исследованиях по фемтосекундном возбуждении молекулярных систем в капле.

\section{Заключение}

B работе представлен разработанный метод Vis-IRвозбуждения электронно-колебательных состояний молекул в конденсированных средах, который получил апробацию в научных работах авторов [19,20,21,28,29], а на практике получены новые научные данные.

1.Создана комбинированная лазерная установка и разработана методика двойного лазерного стационарного $(\lambda=532 \mathrm{~nm})$ и импульсного $\left(\tau_{\mathrm{IR}}=100 \mathrm{~ms}\right)$ ИК-возбуждений $\left(\tau_{\mathrm{IR}}=10.6 \mu \mathrm{m}\right)$ молекул эозина с НЧ лазерного абляционного серебра (средний радиус НЧ составлял $38 \mathrm{~nm})$ в водяных каплях $(d=1.92 \mathrm{~mm})$ в диапазоне температур от 50 до $0.2^{\circ} \mathrm{C}$.

2. Установлено, что при Vis-IR-возбуждении водяной капли происходит импульсный нагрев электронноколебательных состояний системы триплетных уровней молекул эозина с ускорением интеркомбинационных переходов $T_{1} \rightarrow S_{1}$ и высвечиванием замедленной флуоресценции - термолюминесценции (ТЛ). С понижением температуры капли от комнатной до $0.2^{\circ} \mathrm{C}$ наблюдается экспоненциальное затухание ТЛ эозина в различных микрочастях капли вдоль диаметра капли. При этом изменяется спектральный состав свечения ТЛ из-за уменьшения энергии колебаний в результате уменьшения количества колебательных $-\mathrm{H}-\mathrm{O}-\mathrm{H}-$ групп. 
3. Впервые в охлажденной водяной капле обнаружено плазмонное усиление ТЛ молекул эозина при наличии в растворе абляционных НЧ серебра по сравнению с чистыми средами, причем в исследованных низкотемпературных растворах (до $0.2^{\circ} \mathrm{C}$ ) увеличение эффективности плазмонных процессов мало изменяется от концентрации НЧ.

4. Обнаружена высокоинтенсивная ТЛ молекул эозина в малой капле $(d=1.0 \mathrm{~mm})$ после Vis-IR-возбуждения, в результате чего в капле возникает конвективная тепловая волна, распространяющаяся по сложной траектории по поверхности и в объеме со скоростью $0.8 \mathrm{~cm} / \mathrm{s}$. Проведено моделирование процессов теплопередачи в капле при образовании тепловой волны.

\section{Финансирование работы}

Исследование проведено в рамках проекта Государственного Минобрнауки РФ в сфере научной деятельности: (проект № 3.5022.2017/8.9).

\section{Конфликт интересов}

Авторы заявляют, что у них нет конфликта интересов.

\section{Список литературы}

[1] Тарасевич Ю.Ю. // УФН. 2004. Т. 174. № 7. С. 779-790.

[2] $H u$ D., Wu H. // Int. J. Therm. Sc. 2015. Vol. 96. P. 149-159. DOI: https://doi.org/10.1016/j.jthermalsci.2015.05.004

[3] Мыслицкая Н.А., Хитрин А.В., Иванов А.М., Самусев И.Г. // Изв. вузов. Физика. 2011. T. 54. № 11. C. 95-99. [Myslitskaya N.A., Khitrin A.V., Ivanov A.M., Samusev I.G., Bryukhanov V.V. // Russ. Phys. J. 2012. Vol. 54. N 11. P. 1280-1285.]

DOI: $10.1007 / \mathrm{s} 11182-012-9743-3$

[4] Legros J.C., Piskunov M.V. // Intern. J. Multiphase Flow. 2018. Vol. 102. P. 64-76. https://doi.org/10.1016/j.ijmultiphaseflow.2018.01.020

[5] Koshel E.I., Chelushkin P.S., Melnikov A.S., Serdobintsev P.Yu., Stolbovaia A.Yu., Shcheslavskiy V.I., Chernyavskiy O., Gaginskaya E.R., Koshevoy I.O., Tunik S.P. // J. Photochem. Photobiol., A: Chemistry. 2017. N 322. P. $122-130$.

[6] George O., Xiao J., Rodrigo C., Mercade-Prieto R., Sempere J., Chen X. // Chem. Eng. Sci. 2017. Vol. 165. P. 33-47. DOI: $10.1016 /$ j.ces.2017.02.038

[7] Liu G., Cao H.. Хи J. // Solar Energy. 2018. Vol. 170. P. 184-191. DOI: 10.1016/j.solener.2018.05.069

[8] Sazhin S.S., Rybdylova O., Pannala A.S., Somavaraparu S., Zaripov S.K. // Intern. J. Heat Mass Transfer. 2018. Vol. 122. P. 451-458. DOI: 10.1016/j.ijheatmasstransfer.2018.01.094

[9] Волков К.Н., Булат П.В., Ильина Е.Е. // Научно-технический вестник информационных технологий, механики и оптики. 2016. Т. 16. № 5. С. 764-772.

[10] Апексимов Д.В., Букин О.А., Быкова Е.Е., Гейни Ю.Э., Голик С.С., Землянов А.А., Землянов Ал.А., Ильин А.А., Кабанов А.М., Матвиенко Г.Г., Ошлаков В.К., Соколова Е.Б., Хабибуллин Р.Р. // Прикладная физика. 2011. № 6. C. 13-21.
[11] Al-Sharafi A., Yilbas B.S., Ali H. // Intern. J. Heat Mass Transfer. 2018. Vol. 122. P. 749-764.

https://doi.org/10.1016/j.jheatmasstransfer.2018.02.032

[12] Volkov R.S., Strizhak P.A. // Int. J. Therm Sci. 2018. Vol. 127. P. $126-141$

DOI: https://doi.org/10.1016/j.jthermalsci.2018.01.027

[13] Meng G., Jiang L., Li X., Xu Y., Shi X., Yan R., Lu Y. // Appl. Surf. Sci. 2017. Vol. 410. N 15. P. 22-28. https://doi.org/10.1016/j.apsusc.2017.03.079

[14] Lebedev-Stepanov P.V., Rudenko O.V. // Acoust. Phys. 2016. Vol. 62. N 4. P. 414-417. DOI: 10.1134 S1063771016040114

[15] Xiao C., Zhou L., Sun Z., Du X., Yang Y. // Experimental Thermal. and Fluid. Sci. 2016. Vol. 72. P. 210-217. DOI: https://doi.org/10.1016/j.expthermflusci.2015.11.013

[16] Soret C. // Arch. Sci. Phys. Nat. 1879. Vol. 2. P. 48-61.

[17] Де Гроот С., Мазур П. Неравновесная термодинамика. М.: Мир, 1964. 452 с.

[18] Иванов В.И., Ливашвили А.И., Окишев К.Н. // Изв. вузов. Приборостроение. 2008. Т. 51. № 3. С. 50-53.

[19] Bryukhanov V.V., Minaev B.F., Tcibulnikova A.V., Tikhomirova N.S., Slezhkin V.A. // J. Opt. Technol. 2014. Vol. 81. N 11. P. 625-630.

[20] Konstantinova E.I., Minaev B.F., Tsibul'nikova A.V., Borkunov R.Yu., Tsarkov M.V., Antipov A.Yu., Samusev I.G., Bryukhanov V.V. // Opt. and Spectr. 2018. Vol. 125. P. 874-881. DOI: 10.1134/S0030400X19020152

[21] Myslitskaya N.A., Borkunov R.Yu., Tsar'kov M.V., Slezhkin V.A., Samusev I.G., Bryukhanov V.V. // Russ. J. Phys. Chem. A. 2019. Vol. 93. N 8. P. 1559-1566.

[22] Chen P.H., Chen H.H., Anbarasan R., Kuo L.-S. // 2010 IEEE Nanotechnology Materials and Devices Conference (NMDC) Oct 12-15, 2010, Monterey, California, USA. Synthesis and characterization of Eosin Y functionalized MWCNT.

[23] Варгабтик Н.Б. Справочник по теплофизическим свойствам газов и жидкостей. М.: Наука, 1972. 720 с.

[24] Паркер С. Фотолюминесценция растворов. М.: Мир, 1972. $512 \mathrm{c}$.

[25] Смит А. Прикладная ИК-спектроскопия / Пер. с англ. М.: Мир, 1982. $328 \mathrm{c.}$

[26] Макаров А.А., Малиновский А.Л., Рябов Е.А. // УФН. 2012. T. 182. № 10. C. 1047-1080.

[27] Защепина Г.Н. Физические свойства воды. М.: Изд-во МГУ, $1998.184 \mathrm{c}$.

[28] Samusev I.G., Borkunov R.Yu., Tsarkov M.V., Konstantinova E.I., Antipov Y.N., Demin M.V., Bryukhanov V.V. // Nanophotonics and Micro/Nano Optics International Conference 2017 IOP Publishing IOP Conf. Series: Journal of Physics: Conf. Series 961. 2018. 012011 DOI: $10.1088 / 1742-6596 / 961 / 1 / 012011$.

[29] Константинова Е.И., Боркунов Р.Ю., Царьков М.В., Самусев И.Г., Антипов Ю.Н., Брюханов В.В. // ЖПС. T. 86. 2019. T. 2. С. 217-223.

[30] Кондратьев Г.М. Регулярный тепловой режим. М.: Гостехиздат, 1954. $408 \mathrm{c}$.

[31] Камья Ф.М. Импульсная теория теплопроводности / Пер. с франц. под ред. А.В. Лыкова. М.: Энергия, 1972. 272 с. 
[32] Лыков А.В. Теория теплопроводности. М.: Высшая школа, 1966. $592 \mathrm{c}$

[33] Лыков А.В., Берковский Б.М. Конвекция и тепловые волны. М.: Энергия, 1974. 336 с.

[34] Климов В.В. Наноплазмоника. М.: Физматлит, 2009. 480 с.

[35] Автореф. канд. дис. Рыжков И.И. Структуры и устойчивость конвективных течений в чистых жидкостях и многокомпонентных смесях с эффектом термодиффузии: Институт вычислительного моделирования СО РАН. Красноярск. 2014. 